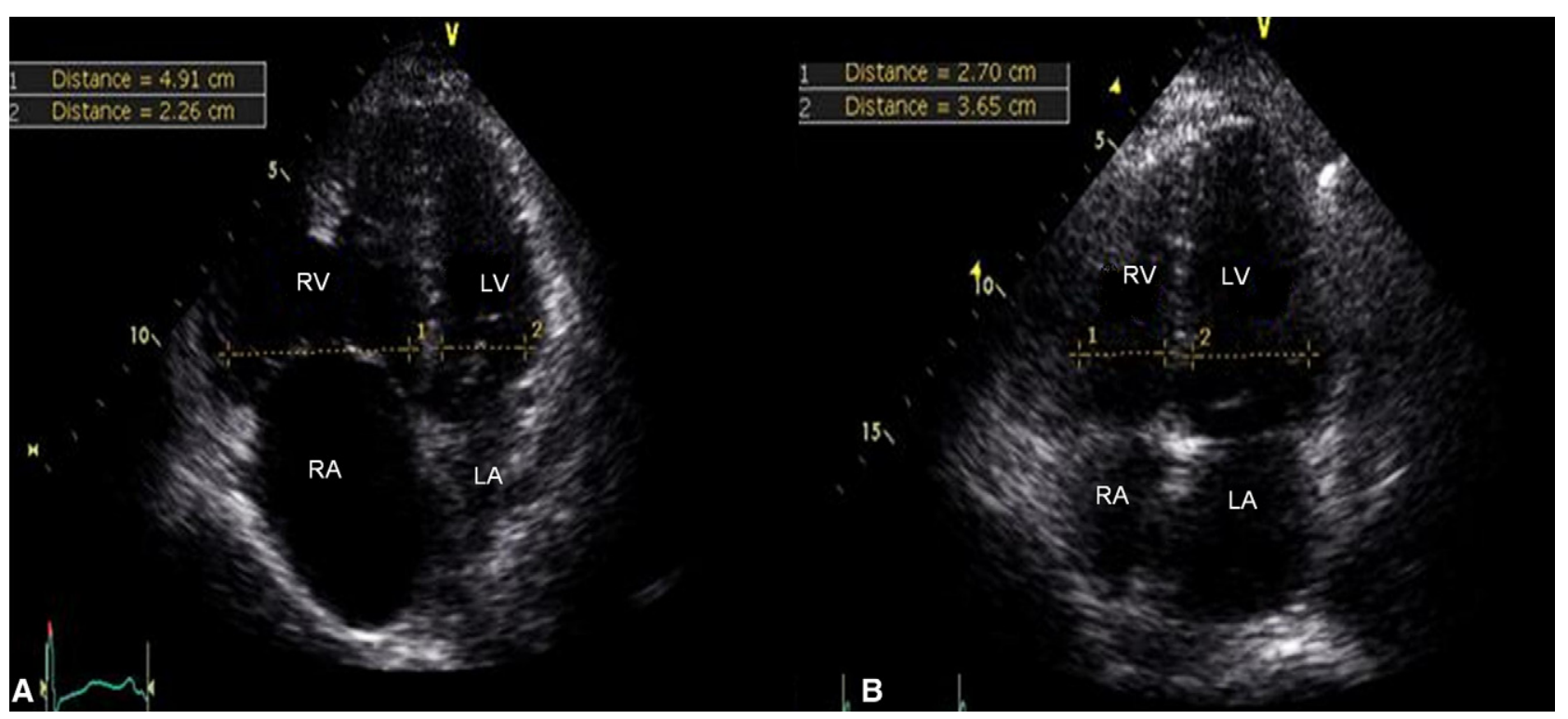

FIGURE 2. Transthoracic echocardiogram pretransplant (A) and posttransplant (B), showing changes in right and left ventricular diameters. $L A$, Left atrium; $L V$, left ventricle; $R A$, right atrium; $R V$, right ventricle.

ventricular dysfunction seen in patients undergoing LTx for pulmonary hypertension ${ }^{4}$ were associated with the mechanism of regurgitation in this case. The influence of the tricuspid annuloplasty remains unclear, requiring further analysis.

\section{CONCLUSIONS}

We report this unusual case because it demonstrates a rare mechanism of MR after LTx requiring surgical repair. Close observation of left ventricular and mitral annular anatomy is necessary after LTx in patients with severe pulmonary hypertension. Inverse remodeling of the left-sided structures could be associated with clinically relevant, new-onset MR.

\section{References}

1. Saxena P, Clarke B, Dunning J. Aspergillus endocarditis of the mitral valve in a lung-transplant patient. Tex Heart Inst J. 2007;34:95-7.

2. Scherer M, Fieguth HG, Aybek T, et al. Disseminated Aspergillus fumigatus infection with consecutive mitral valve endocarditis in a lung transplant recipient. J Heart Lung Transplant. 2005;24:2297-300.

3. Khouzam R, D'Cruz I, Arroyo M. Systematic scleroderma with moderate to severe mitral regurgitation: unusual three-dimensional echocardiographic features. Can J Cardiol. 2008;24:152

4. Bîrsan T, Kranz A, Mares P, et al. Transient left ventricular failure following bilateral lung transplantation for pulmonary hypertension. J Heart Lung Transplant. 1999;18:304-9.

\title{
Third-time lung transplantation in a patient with cystic fibrosis
}

Nakul Vakil, MD, David P. Mason, MD, James J. Yun, MD, PhD, Sudish C. Murthy, MD, PhD, Marie M. Budev, DO, and Gosta B. Pettersson, MD, PhD, Cleveland, Ohio

From the Department of Thoracic and Cardiovascular Surgery, Heart and Vascular Institute, Cleveland Clinic, Cleveland, Ohio.

Disclosures: Authors have nothing to disclose with regard to commercial support.

Received for publication Aug 2, 2010; accepted for publication Sept 2, 2010; available ahead of print Nov 19, 2010.

Address for reprints: David P. Mason, MD, Department of Thoracic and Cardiovascular Surgery, Heart and Vascular Institute, Cleveland Clinic, 9500 Euclid Avenue/Desk J4-1, Cleveland, OH 44195 (E-mail: masond2@ccf.org).

J Thorac Cardiovasc Surg 2011;141:e3-5

$0022-5223 / \$ 36.00$

Copyright (c) 2011 by The American Association for Thoracic Surgery doi:10.1016/j.jtcvs.2010.09.028
Respiratory failure is the leading cause of death in patients with cystic fibrosis (CF), and lung transplantation (LTx) is the only treatment option for patients with end-stage disease. Unfortunately, the long-term success of LTx is limited by the development of bronchiolitis obliterans syndrome (BOS), and retransplantation (re-LTx) for these patients is infrequent and controversial. ${ }^{1-4}$ Concerns include (1) the technical difficulty of re-LTx; (2) immunologic barriers imparting worse survival in patients whose first grafts 
have already failed; and (3) the appropriateness of reallocating them a scare resource. Because patients with $\mathrm{CF}$ tend to be the youngest patients undergoing LTx, the need for re-LTx and even multiple re-LTxs may become increasingly common. Third-time LTx has been reported only once and never in a patient with $\mathrm{CF}^{5}$ This case highlights the feasibility and good mid-term survival of third-time LTx in a patient with CF.

\section{CLINICAL SUMMARY}

A 25-year-old man with a history of CF and insulindependent diabetes mellitus presented to the Cleveland Clinic with BOS after his second double lung transplant (DLTx) at another institution. His medical history included a diagnosis of $\mathrm{CF}$ as an infant with the eventual development of respiratory failure necessitating DLTx with atrial septal defect repair at age 17 years. He did well for 4 years, at which point he became dyspneic. He was treated for presumed rejection with pulse steroids and OKT3 but eventually had worsening respiratory failure secondary to BOS. He underwent re-DLTx 6 years after his initial DLTx and had a smooth postoperative course. However, after only 1 year, he noted worsening dyspnea. Despite immunologic interventions, including antithymocyte globulin, photopheresis, methotrexate, and pulse steroids, severe BOS again developed. He had no ongoing posttransplant infectious complications or resistant organisms. He presented to the Cleveland Clinic for consideration of third-time LTx, 8 years after his first LTx and 2 years after his second LTx.

The patient was ambulatory, required 2 liters continuous oxygen, and had a forced expiratory volume at 1 second of $12 \%$ of predicted, a body mass index of $14.7 \mathrm{~kg} / \mathrm{m}^{2}$, and normal renal function. His panel reactive antibody level was $15 \%$ with specificity only to human leukocyte antigen locus DQ4. His medications included prednisone $10 \mathrm{mg}$ per day, tacrolimus, mycophenolate mofetil, and azithromycin. Given his preserved fitness despite severe single-system organ dysfunction, young age, and relatively long period of survival after his transplants, the patient was listed for third-time DLTx. His lung allocation score was 36.4.

An appropriate donor became available after 1 month, and the patient underwent third-time DLTx. At surgery, the chest was entered through the previous transverse sternothoracotomy. There were dense pleural adhesions bilaterally that were lysed using electrocautery off of cardiopulmonary bypass. However, after complete mobilization of the lungs and intrapericardial dissection, severe hypercapnia and accompanying hemodynamic instability necessitated institution of right atrial to ascending aortic cardiopulmonary bypass. Sequential DLTx was then performed with only slight modification from standard implantation techniques. Recipient pneumonectomies were carried out, and the airways were trimmed back proximal to the old anastomoses. However, the pulmonary artery and left atrium were transected distal to the previous vascular anastomoses to allow further sewing length and then easily approximated to the donor tissue. Total ischemic time was 5 hours and 40 minutes, and total cardiopulmonary bypass time was 3 hours and 17 minutes. The pathology of the explanted lungs showed acute and chronic bronchiolitis with bronchiectasis.

The patient's postoperative course was complicated by reoperation for hemothorax evacuation on postoperative day 2 and closure of a small parenchymal airleak on postoperative day 11 . The patient otherwise did well and was discharged on postoperative day 23. At 24 months after his third-time DLTx, he had a clear radiograph with slight left hemidiaphragm elevation (Figure 1), no clinical rejection episodes with all transbronchial biopsies graded A0B0, no dyspnea, and a forced expiratory volume at 1 second that was stable at $53 \%$ of predicted.

\section{DISCUSSION}

Although third-time LTx is rare, even second-time transplantation is infrequent and controversial. ${ }^{6}$ Because of the infrequency of re-LTx, there are few series examining outcomes. The largest study, by Kawut and colleagues, ${ }^{4}$ evaluated the entire US experience of re-LTx. Although survival was worse after re-LTx, it was improved in the most modern retransplant cohort and only slightly worse than primary transplantation. Risk factors for mortality included re-LTx within 30 days of primary LTx and being on mechanical

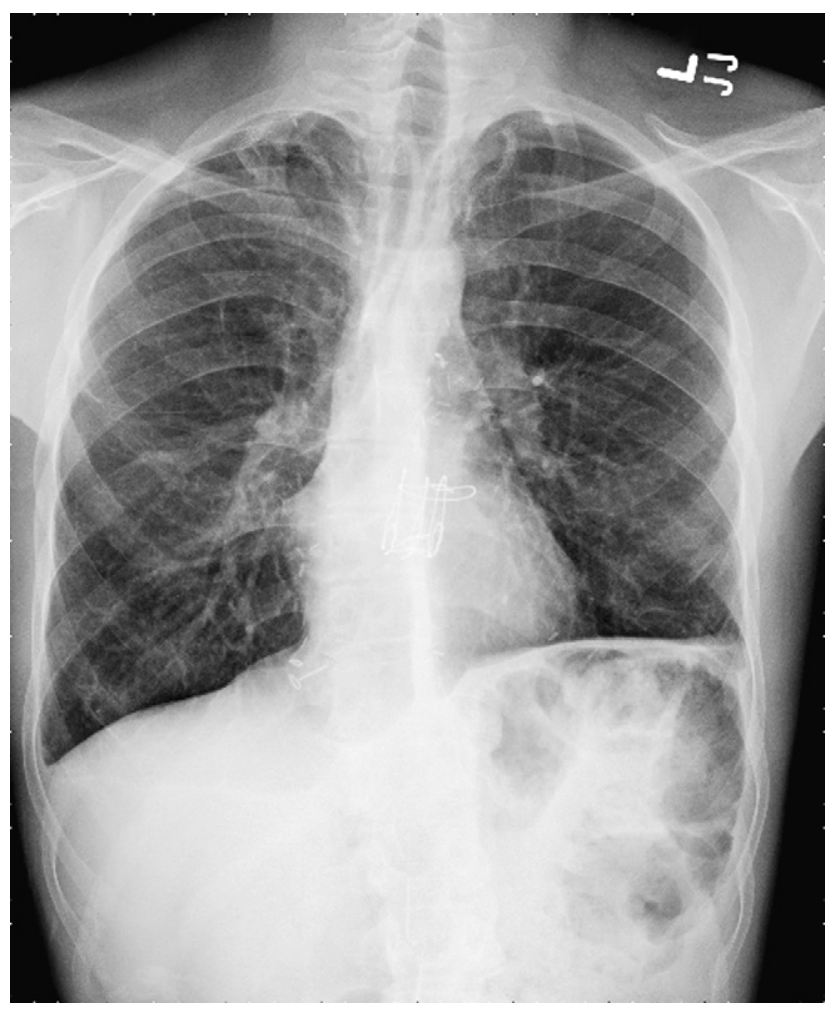

FIGURE 1. Chest radiograph 24 months after third-time DLTx. 
ventilation at the time of re-LTx. Although our patient had severe respiratory compromise, he had preserved muscle mass, was several years removed from his most recent transplant, and had no other organ system failure such as renal dysfunction.

BOS remains the main cause of chronic graft dysfunction after LTx, and retransplantation is the only definitive treatment. ${ }^{6}$ Freedom from BOS in patients with $\mathrm{CF}$ receiving LTx is disappointingly low, only $38 \%$ at 10 years. ${ }^{7}$ Because of their young age at initial transplantation, an increasing number of patients with CF may eventually require re-LTx and perhaps even multiple transplants. ${ }^{8}$ This case report is the first to describe third-time LTx in this patient population.

Our initial concern when considering this patient for third-time surgery was that pleural adhesions that often accompany suppurative lung disease might prove problematic in the reoperative setting. Although pleural adhesions were noted to be significant and likely contributed to the complication of postoperative hemothorax, they were not prohibitive. An additional concern was that the patient might have early BOS given his shortened BOS-free survival after the second LTx when compared with the first. However, at 24 months since his transplant, the patient has had no evidence of acute or chronic rejection. In the only other report of a patient undergoing third-time LTx, in Australia, a Maastricht category IV donor after cardiac death was used because of ethical concerns about appropriate organ allocation. ${ }^{5}$ The authors suggest that this "extended criteria" donor otherwise would not have been used. The lung allocation score and system of organ allocation preclude such an approach in the United States, and the ethical debate regarding organ allocation for retransplantation remains unresolved.

\section{CONCLUSIONS}

Clearly, this is a single patient outcome, and this report should not be considered an endorsement of broad adoption of third-time LTx. However, this case demonstrates the feasibility and good mid-term survival of a third-time LTx with no obvious early immune-mediated dysfunction. Larger series of third-time transplant recipients will be necessary to determine the appropriateness of this aggressive therapy.

\section{References}

1. Novick RJ, Stitt LW, Al-Kattan K, et al. Pulmonary retransplantation: predictors of graft function and survival in 230 patients. Pulmonary Retransplant Registry. Ann Thorac Surg. 1998;65:227-34.

2. Brugiere $\mathrm{O}$, Thabut $\mathrm{G}$, Castier Y, et al. Lung retransplantation for bronchiolitis obliterans syndrome: long-term follow-up in a series of 15 recipients. Chest. 2003; 123:1832-7.

3. Strueber M, Fischer S, Gottlieb J, et al. Long-term outcome after pulmonary retransplantation. J Thorac Cardiovasc Surg. 2006;132:407-12.

4. Kawut SM, Lederer DJ, Keshavjee S, et al. Outcomes after lung retransplantation in the modern era. Am J Respir Crit Care Med. 2008;177:114-20.

5. Oto T, Rowland M, Griffiths AP, et al. Third-time lung transplant using extended criteria lungs. Ann Thorac Surg. 2007;84:642-4.

6. Kotloff RM. Lung retransplantation: all for one or one for all? Chest. 2003;123 1781-2.

7. Meachery G, De Soyza A, Nicholson A, et al. Outcomes of lung transplantation for cystic fibrosis in a large UK cohort. Thorax. 2008;63:725-31.

8. Morton J, Glanville AR. Lung transplantation in patients with cystic fibrosis Semin Respir Crit Care Med. 2009;30:559-68.

\title{
Acute limb ischemia after internal thoracic artery harvesting: A case report
}

\author{
Linda M. de Heer, MD, Marc P. Buijsrogge, MD, and Jaap R. Lahpor, MD, Utrecht, The Netherlands
}

The use of the left internal thoracic artery and/or right internal thoracic artery for coronary revascularization is preferable to ensure prolonged graft patency. ${ }^{1}$ We report the case of a 69 -year-old man who underwent coronary artery bypass

\footnotetext{
From the Department of Cardio-Thoracic Surgery, Division of Heart and Lungs, University Medical Center, Utrecht, The Netherlands.

Disclosures: Authors have nothing to disclose with regard to commercial support.

Received for publication May 25, 2010; revisions received July 2, 2010; accepted for publication Sept 10, 2010; available ahead of print Oct 29, 2010.

Address for reprints: Linda M. de Heer, MD, Department of Cardio-Thoracic Surgery, University Medical Center Utrecht, PO Box 85500, 3508 GA Utrecht, The Nether-

lands (E-mail: L.M.deheer-2@umcutrecht.nl).

J Thorac Cardiovasc Surg 2011;141:e5-7

$0022-5223 / \$ 36.00$

Copyright (c) 2011 by The American Association for Thoracic Surgery

doi:10.1016/j.jtcvs.2010.09.030
}

grafting in which harvesting of the left internal thoracic artery resulted in critical ischemia of the left limb, leaving upper leg amputation as the only option. This patient had a long-standing occlusion of the distal abdominal aorta and the left and right common iliac arteries with an open external iliac and left common femoral artery and completely relied on the internal thoracic arteries as the major source of blood supply to the legs. A recommendation for the management of patients with indications for coronary artery bypass grafting and aorto-iliac occlusive disease is given.

\section{CLINICAL SUMMARY}

A 69-year-old man was admitted to the hospital because of chronic stable angina pectoris. On physical examination, 